\title{
Overlapping MRI findings in progressive supranuclear palsy - corticobasal syndrome
}

\section{Sobreposição de achados na RM da paralisia supranuclear progressiva - síndrome corticobasal}

Eduardo Della Valle Prezzi ${ }^{1}$, Luiz Felipe Vasconcellos ${ }^{1}$, Victor Hugo Marussi ${ }^{2,3}$

A 59 year old woman presented with an atypical parkinsonian syndrome with clinical and neuroimaging features of corticobasal syndrome (CBS) and progressive supranuclear palsy (PSP). CBS manifestations were slurred/scanning speech and asymmetrical right signs: levitation phenomena, pseudo-hemiparetic gait and hypertonia/hyperreflexia. PSP signs were staring face and oculomotor apraxia. Neuroimaging revealed midbrain atrophy with asymmetrical
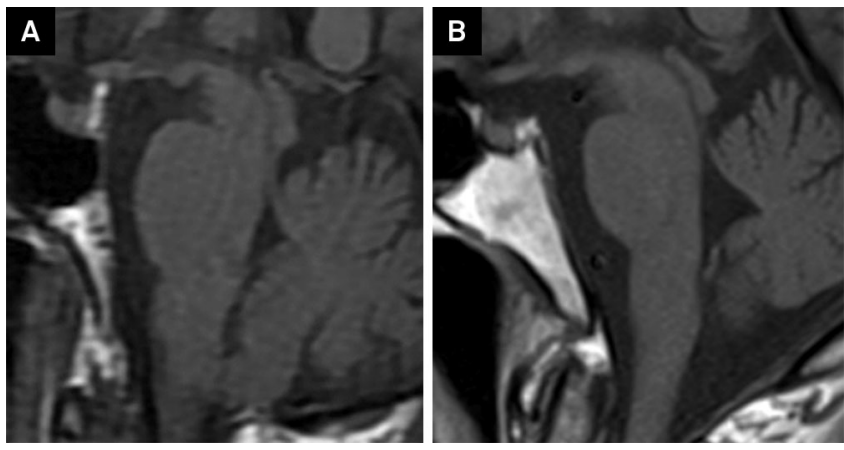

Figure 1. Sagital T1 weighted image at the midline shows reduction of anteroposterior midbrain diameter $(1.4 \mathrm{~cm}-$ Normal Range $(N R)>1.8 \mathrm{~cm})$ and tegmental size reduction $(0.95 \mathrm{~cm}-\mathrm{NR}>1.15 \mathrm{~cm})$; Age matched control midbrain. cerebral peduncle (CP), tegmental hiperintensity (Figure 1 to 4) and frontal and midbrain hypometabolism (Figure 5).

Typical Magnetic Resonance Image (MRI) of PSP presents with midbrain atrophy ${ }^{1}$ and hiperintensity ${ }^{2}$ while CBS displays asymmetrical frontoparietal and $\mathrm{CP}$ atrophy.

This case has been clinically classified as PSP-CBS ${ }^{4}$ but definite diagnosis is through neuropathology.

Figure 2. Axial T2 weighted image in high frontoparietal convexity showing no cortical asymmetry.

\footnotetext{
'Instituto de Neurologia Deolindo Couto, Universidade Federal do Rio de Janeiro, Rio de Janeiro RJ, Brazil;

${ }^{2}$ Med Imagem, Hospital Beneficência Portuguesa de São Paulo, Sao Paulo SP, Brazil;

${ }^{3}$ Centro Medicina Nuclear da Guanabara, Rio de Janeiro RJ, Brazil.

Correspondence: Eduardo Prezzi; Instituto de Neurologia Deolindo Couto; Av Venceslau Bras, 95 Botafogo; 22290-140 Rio de Janeiro RJ, Brazil:

E-mail: eduardoprezzi@gmail.com

Conflict of interest: There is no conflict of interest to declare.
}

Received 13 February 2014; Received in final form 10 April 2014; Accepted 30 April 2014. 


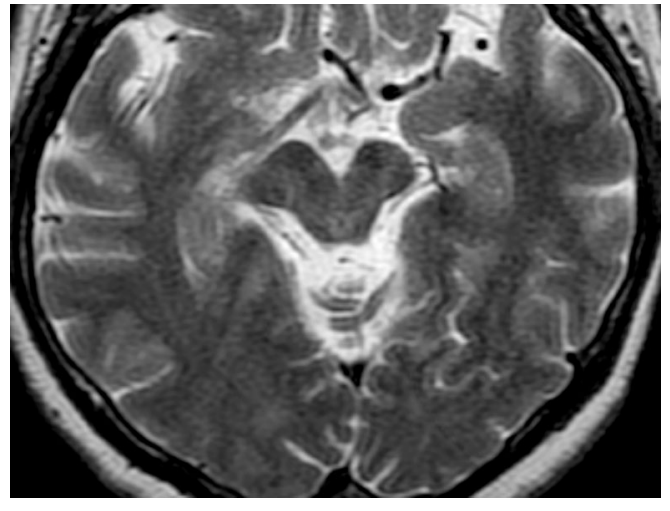

Figure 3. Axial T2 weighted image at midbrain level displays anteroposterior midbrain size reduction $(1.2 \mathrm{~cm}-\mathrm{NR}>1.8 \mathrm{~cm})$ and marked cerebral peduncle asymmetry (right CP $1.53 \mathrm{~cm}$ and left CP $1.26 \mathrm{~cm})$.
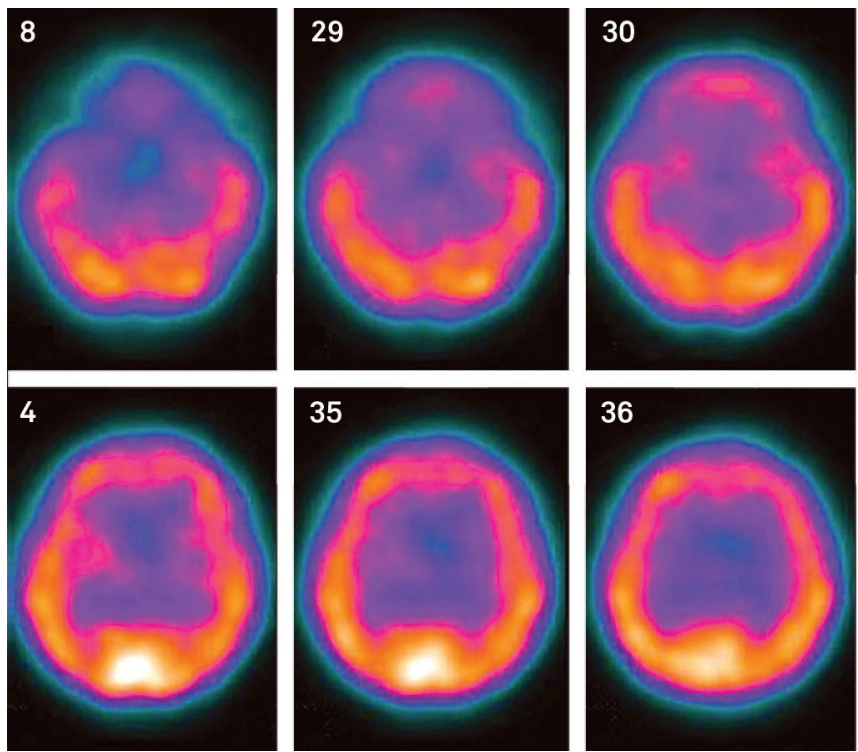
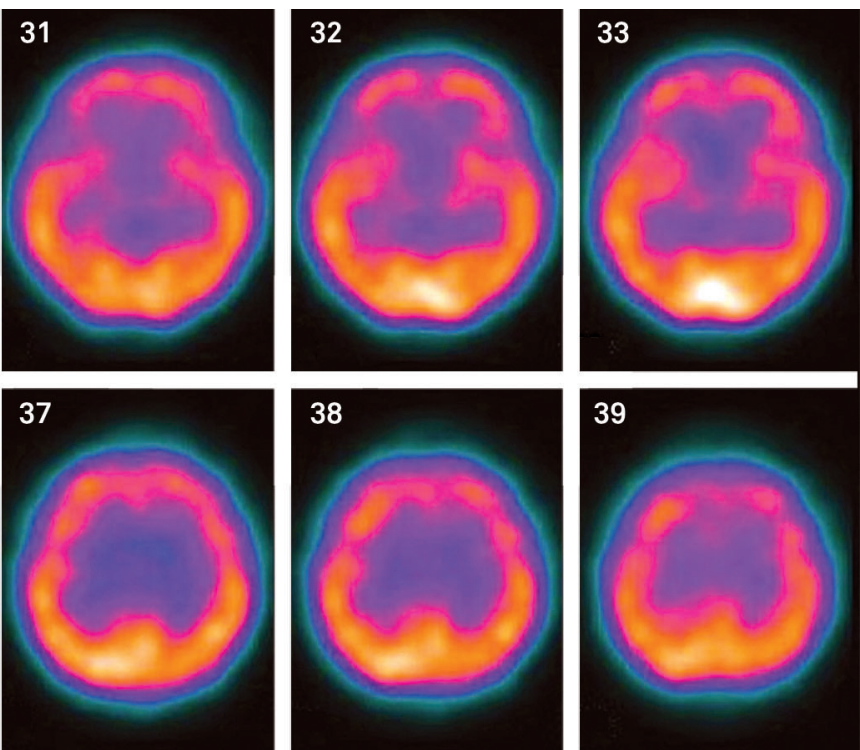

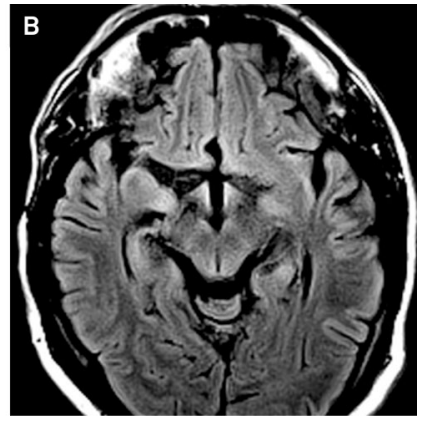

Figure 4. Axial FLAIR image shows increased tegmental signal intensity compared to age matched control.

Figure 5. Technetium SPECT showing symmetrical frontal lobe and midbrain hypoperfusion.

\section{References}

Massey LA, Jäger HR, Paviour DC, et al. The midbrain to pons ratio: a simple and specific MRI sign of progressive supranuclear palsy. Neurology 2013;80:1856-1861.

2. Righini A, Antonini A, De Notaris R, et al. MR imaging of the superior profile of the midbrain: differential diagnosis between progressive supranuclear palsy and Parkinson disease. AJNR Am J Neuroradiol 2004;25:927-932
3. Koyama M, Yagishita A, Nakata Y, Hayashi M, Bandoh M, Mizutani T. Imaging of corticobasal degeneration syndrome. Neuroradiology 2007;49:905-912.

4. Williams DR, Lees AJ. Progressive supranuclear palsy: clinicopathological concepts and diagnostic challenges. Lancet Neurol 2009;8:270-279 